$\begin{array}{ll} & \text { Etnográfica } \\ \text { etnográfica } & \text { Revista do Centro em Rede de Investigação em }\end{array}$

Antropologia

vol. $15(3) \mid 2011$

Vol. $15(3)$

\title{
Identidade e pertença: para além das dimensões materiais do sofrimento social
}

Identity and belonging: beyond the material dimensions of social suffering

\author{
Elizabeth Pilar Challinor
}

\section{OpenEdition}

Journals

Edição electrónica

URL: https://journals.openedition.org/etnografica/1044

DOI: 10.4000/etnografica.1044

ISSN: 2182-2891

\section{Editora}

Centro em Rede de Investigação em Antropologia

\section{Edição impressa}

Data de publição: 1 outubro 2011

Paginação: 479-500

ISSN: 0873-6561

\section{Refêrencia eletrónica}

Elizabeth Pilar Challinor, «Identidade e pertença: para além das dimensões materiais do sofrimento social», Etnográfica [Online], vol. 15 (3) | 2011, posto online no dia 20 julho 2012, consultado o 12 fevereiro 2022. URL: http://journals.openedition.org/etnografica/1044 ; DOI: https://doi.org/10.4000/ etnografica.1044

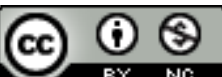

Etnográfica is licensed under a Creative Commons Attribution-NonCommercial 4.0 International License. 


\title{
Identidade e pertença: para além das dimensões materiais do sofrimento social
}

\section{Elizabeth Pilar Challinor}

\begin{abstract}
Um olhar antropológico sobre as relações sociais em dois microcosmos etnográficos - um bairro e um centro de saúde - revela as limitações de encarar a pobreza material como o único critério para compreender os processos de sofrimento social. De forma a explorar como o sofrimento social pode ser vivenciado através das identificações e das pertenças, a identidade étnica e a identidade profissional são examinadas como exemplos da identidade social em geral. A relação dialética entre a identidade social e a identidade pessoal demonstra como o poder não está depositado nas pessoas, mas depende das suas relações sociais. Dado que o exercício de poder não pode ser garantido pelo simples estatuto de uma determinada categoria social, urge procurar vivências e subjetividades nas fissuras das categorias, distinguindo entre uma categoria de prática e uma categoria de análise, de forma a alargar o horizonte sobre a natureza dos processos de sofrimento social.
\end{abstract}

PALAVRAS-CHAVE: Cabo Verde, identidade, prática biomédica.

NO SEU LIVRO THE WEIGHT OF THE WORLD: SOCIAL SUFFERING IN Contemporary Society, Bourdieu (1999) argumenta que, se a pobreza material servir, nas ciências sociais, como o único critério para analisar o sofrimento social, será difícil descobrir todo o tipo de sofrimento social que existe nas sociedades contemporâneas. ${ }^{1}$ Bourdieu refere-se, mais especificamente, às categorias sociais - profissionais que trabalham no âmbito da luta contra a pobreza - que ocupam lugares inferiores nos microcosmos onde estão inseridos, que não deixam de ser contextos privilegiados, em termos materiais,

l Agradeço a Rosa Silva as correções do português e as críticas e sugestões feitas a versões anteriores deste texto por Micol Brazzabeni, Chiara Pusssetti, Teresa Joaquim, Jeremias Carvalho e o parecerista anónimo. Todas as limitações do texto são da minha responsabilidade. 
comparados com outros microcosmos. Se adotarmos o ponto de vista do macrocosmo, o seu sofrimento torna-se relativo e quase insignificante comparado com o "verdadeiro" sofrimento de pobreza material. Porém, segundo Bourdieu, se não houver espaço para incluir a dimensão subjetiva do sofrimento destas categorias sociais, o estudo do sofrimento social será incompleto, por deixar de parte aquilo que ele considera serem vários tipos de "sofrimento vulgar" que ocorrem no quotidiano (1999: 4).

A forma como cada categoria social vive e sente o posicionamento que ocupa na sociedade é afetada pelas interações sociais que ocorrem dentro dos microcosmos sociais, tais como a família alargada, o trabalho e a vizinhança (Bourdieu 1999: 4). Estas interações sociais poderão ser fonte de sofrimento social coletivo ou individual, quando, por exemplo, contribuem para o isolamento, para a exclusão e para o desempoderamento (disempowerment) das pessoas.

Ao adotar esta perspetiva, o objetivo deste artigo é examinar as formas como o sofrimento social pode ser vivenciado, dentro de microcosmos sociais, através das identificações e das pertenças. A fundamentação para esta análise provém dos argumentos de Maalouf (2003) sobre a identidade e as pertenças, da abordagem cognitiva de Brubaker (2004) na sua análise da etnicidade, e do realismo crítico das teorias desenvolvidas por Archer $(2000,2003)$ sobre a relação dialética entre a identidade social e a identidade pessoal.

Maalouf (2003: 19-20) afirma que cada indivíduo tem, sem exceção, uma identidade composta de muitas afiliações ou pertenças. Ao isolar uma das suas pertenças, o indivíduo pode partilhar uma espécie de parentesco com uma grande quantidade de seres humanos, mas, juntando-as todas, encontra a sua identidade pessoal e única. As pessoas são levadas a vivenciar a sua identidade como se tivessem uma única afiliação ou pertença, segundo Maalouf, quando sentem que essa afiliação está a ser ameaçada (2003: 26). Embora o objetivo de Maalouf seja o de tentar compreender o que leva as pessoas a cometerem massacres "em nome da identidade", o objetivo da abordagem aqui adotada é outro. Trata-se de investigar o "sofrimento vulgar" dos microcosmos em dois casos etnográficos - um bairro e um centro de saúde - onde a identidade de uma pessoa é reduzida a uma única afiliação, através das suas relações sociais.

O primeiro caso etnográfico refere-se a uma mãe cabo-verdiana, imigrante em Portugal, envolvida em conflitos com os seus vizinhos, que expressava através das supostas rivalidades "intraétnicas" entre sampajudus - cabo-verdianos originários das ilhas de Barlavento - e badius - cabo-verdianos originários das ilhas de Sotavento. O segundo caso refere-se a uma médica que atendia a criança da mãe cabo-verdiana, cuja identidade profissional de pediatra, a trabalhar rodeada de médicos de família, constituía o foco das tensões à volta do qual se disputavam competências e pertenças. ${ }^{2}$ 
Ao escolher estes dois casos, que estão interligados, importa clarificar algumas questões. Em primeiro lugar, estes dois processos de sofrimento acontecem com pessoas que se relacionam, mas os processos, aparentemente, terão pouca relação entre si. Conflitos intraétnicos terão algo a ver com conflitos profissionais? Como já foi referido, ambos os casos descrevem situações em que a pessoa é levada a vivenciar a sua identidade social como se uma única afiliação - étnica, num caso, e profissional, no outro - a definisse. Em segundo lugar, tanto a identidade étnica como a identidade ocupacional devem, segundo Jenkins (1994), ser teorizadas como exemplos da identidade social em geral.

A escolha do caso da pediatra também pretende responder ao apelo de Bourdieu (1999) para criar espaço, na análise, para os pontos de vista das categorias sociais que ocupam uma posição inferior num mundo relativamente mais privilegiado, de forma a investigar o "sofrimento posicional". No caso da pediatra, não se trata de uma posição inferior a nível material; trata-se da falta de reconhecimento do seu trabalho, que, segundo Araújo (2005: 7), "associa, na maioria das vezes, a recusa de autonomia e de poder para os trabalhadores". O exercício do poder não é automaticamente garantido pelo simples estatuto de ser médico, depende das interações sociais no microcosmo social onde o médico está inserido. E, neste caso, o facto de ambas as pessoas dos estudos de caso se relacionarem nas consultas médicas é significativo. A falta de poder que a pediatra sentia nas suas relações profissionais com o pessoal dentro do centro de saúde, que contrasta com o seu exercício de poder médico durante as consultas observadas com a mãe do bairro (e com outras mães cabo-verdianas), evidencia a forma como o poder está "inscrito" (embedded) nas relações sociais (Jenkins 1994: 199).

A análise que apresento em seguida oferece uma reflexão teórica sobre a identidade e as pertenças para enquadrar cada estudo de caso.

\section{QUEM SOU “EU”, QUEM É O "OUTRO”?}

Maalouf (2003: 31) afirma que, quando encaramos a identidade como algo composto por várias pertenças e, ao refletir, constatamos que algumas destas pertenças até são incompatíveis entre si, deixa de ter sentido falar das nossas relações sociais em termos de "nós" e "eles". Ao reconhecer a multiplicidade e incompatibilidade de todas as suas pertenças, um indivíduo que vai à guerra em nome da religião ou da etnia, por exemplo, vai descobrir que existem pessoas no "seu lado" com quem tem pouco em comum e pessoas do "outro lado" com quem poderá ter muitas mais afinidades. Mas quando uma pertença parece estar ameaçada, a necessidade de a defender pode ocultar essas outras afinidades.

Ser alvo de uma "definição externa" que entra em contradição com a "definição interna" que uma pessoa detém da sua própria identidade (Jenkins 1994) pode criar sofrimento social, quando o indivíduo se sente impossibilitado de 
influenciar a perceção que os outros têm de si. Antes de discutirmos como esta vivência pode afetar o self, a primeira questão a abordar é a de como teorizar esse self. ${ }^{3}$

Excluindo a dimensão transcendental da sua abordagem sociológica, Archer (2000: 228) alega que a realidade é feita de três dimensões com as quais nós, seres humanos, lidamos: a natural, que corresponde ao bem-estar físico, a da prática, que corresponde à competência performativa, e a social, que corresponde ao valor próprio na ordem social. A identidade social - o resultado das nossas relações com a sociedade - deve ser distinguida da nossa identidade pessoal, que é mais abrangente, dado que emerge das nossas relações com as três dimensões da realidade. Ambas as identidades estão entrelaçadas e o seu aparecimento é um processo dialético, mas a identidade pessoal é o árbitro que tem de regular as relações do self com toda a realidade. As três dimensões podem estar em conflito: atendendo ao bem-estar físico, o professor, por exemplo, ao fugir de um cão que está a ladrar, e ao fazê-lo à frente dos alunos, pode estar a comprometer a sua competência performativa. É preciso fazer escolhas, separar as preocupações principais das preocupações secundárias, o que acontece através de um constante diálogo interno, testando os compromissos contra os diferentes comentários emocionais. Somos quem somos, alega Archer, por causa daquilo que nos preocupa. Ao estabelecermos as nossas preocupações principais e ao acomodarmos as preocupações secundárias, definimo-nos a nós próprios (Archer 2000: 10). Esta capacidade para a reflexividade não pode ser relegada para a disciplina da psicologia, porque faz parte da prática, interagindo com a socialidade (2000: 194). No entanto, somos mais do que a sociedade faz de nós, devido à nossa capacidade de refletir sobre ela.

Além da distinção entre identidade pessoal e identidade social, Archer (2000, 2003) também separa o "agente" do "ator", o "eu" do "mim". O agente refere-se à nossa posição involuntária face à distribuição dos escassos recursos da sociedade: podemos ser desfavorecidos ou mais privilegiados. Trata-se de uma identidade coletiva. Não escolhemos o meio onde nascemos, que condiciona, mas não determina, os papéis que ocupamos como atores. $\mathrm{O}$ ator existe no singular. Nem todas as pessoas conseguem ser ator, no sentido em que nem todas conseguem encontrar um papel no qual sentem que podem investir a sua pessoa, de forma que a identidade social correspondente exprima a sua identidade pessoal (Archer 2003: 118). O "eu" pode sofrer ao descobrir que se considera que o seu "mim" fala com uma pronúncia errada ou é desprezado pela sua cor ou género e que o seu "eu" não pode fazer nada, nesse momento, para mudar a situação (Archer 2000: 264). Para voltarmos aos argumentos de Maalouf (2003), o "eu" é reduzido a uma ou poucas pertenças e, muitas vezes,

3 Segundo Damásio (2000: 233), não existe uma palavra própria nas línguas românicas para traduzir o conceito de self. 
é a forma como olhamos para o "outro" que o torna prisioneiro. E mesmo que se saiba que as afirmações que produzem generalizações e julgamentos sobre povos inteiros ocultam a sua verdadeira diversidade, tal não deixa de ser uma prática comum. Os estereótipos oferecem o caminho da menor resistência, que pode acabar, nalguns contextos extremos, em derramamentos de sangue. As "nossas palavras" afirma Maalouf, "não são inocentes, nem sem consequência” (2003: 21-22, tradução minha).

Porque é que se continua por este caminho da menor resistência? No que diz respeito aos estereótipos étnicos e raciais, Brubaker (2004) oferece uma explicação para a sua persistência. Na sua abordagem cognitiva, sugere que, em vez de analisar os estereótipos como deficiências cognitivas, como crenças falsas ou exageradas que revelam a natureza preconceituosa de quem os utiliza, os estereótipos devem ser examinados de uma forma mais neutra, como "estruturas cognitivas que contêm conhecimento, crenças e expectativas sobre grupos sociais" (Hamilton e Sherman 1994, em Brubaker 2004: 72). Brubaker afirma que tratar os estereótipos e categorias sociais como representações mentais de objetos sociais elucida a relação entre o indivíduo e o social nos processos de produção e utilização de "moldes" (templates) estandardizados para tirar sentido dos objetos sociais (2004: 73). No caso mais específico das classificações étnicas, os indivíduos são despersonalizados de forma que a pessoa singular seja transformada num exemplar de um grupo qualificado (Levine 1999, em Brubaker 2004: 73). Na terminologia de Archer (2000, 2003), o "eu" vê-se transformado num "mim" - membro de uma coletividade com a qual pode, ou não, identificar-se. No entanto, este mesmo "eu" também não deixa de transformar o "eu" de outras pessoas em membros representativos de coletividades - "eles”. É neste sentido que Brubaker argumenta que uma abordagem cognitiva não equivale a uma abordagem individualista: trata-se de "um conhecimento partilhado socialmente sobre objetos sociais" (2004: 86, tradução minha). Trata-se de examinar fenómenos "sócio-mentais" (Zerubavel 1997, em Brubaker 2004: 86) onde se cruzam a cognição e a cultura. Para este efeito, é preciso estudar os contextos de interação ou "microcosmos sociais" (Bourdieu 1999) onde os estereótipos e categorizações sociais são ativados (Brubaker 2004: 76). E, como afirma Jenkins, também é preciso articular a identidade social com a identidade pessoal:

"[...] social identity must be constructed as a proper subject for theorization in such a way as to allow for the inclusion of individual and collective identities within a unified analytical framework. Even the most private of identities is not imaginable as anything other than the product of a socialised consciousness and a social situation. Even the most collective of identities must in some sense exist in the awareness of individual actors" (Jenkins 1994: 218). 
O primeiro caso etnográfico evidencia o entrelaçamento entre a identidade social e pessoal na forma como a etnicidade é ativada e vivenciada.

\section{ETNICIDADE, GÉNERO E PERTENÇAS}

Depois de ter sido abandonada pelo pai das suas filhas, no bairro espontâneo de cabo-verdianos onde Sara vivia, a relação com os vizinhos mudou drasticamente. O seu "eu" começou a sofrer ao descobrir como o seu "mim" passou a ser tratado em função das rivalidades “intraétnicas” entre sampajudus e badius.

Realizei uma entrevista num banco de um jardim porque Sara não queria levar-me à sua casa, dizendo que, se me levasse, os vizinhos iriam tornar a sua vida ainda mais miserável, acusando-a de estar a pedir ajuda. Nem dentro de casa estava à vontade; uma vez os vizinhos mandaram calar a sua filha quando cantava. Explicou que os vizinhos não gostavam dela por ser sampajudu - "Eles são como os portugueses com os pretos: racistas".

Sara emigrou para Portugal para trabalhar como doméstica na casa de uma senhora portuguesa. Em Cabo Verde, tinha abandonado a escola para ajudar a mãe a sustentar a família. E era a própria mãe quem ia levantar o seu salário, que não podia ser entregue a uma menor. Vir para Portugal fazia parte do imaginário cabo-verdiano do stranjer como um paraíso (Carling e Åkesson 2009: 136) onde iria melhorar as suas condições de vida. Quase todo o dinheiro que ganhava enviava para a mãe em Cabo Verde, mas comia mal na casa da senhora, onde havia outra empregada, portuguesa, que se aproveitava dela para a sobrecarregar de trabalho. Depois conheceu um cabo-verdiano, Carlos. Apaixonou-se por ele e deixou a casa da senhora para viverem juntos numa barraca na cidade. Carlos era muito ciumento e não a deixava estar com os amigos, nem falar ao telemóvel com eles. No entanto, Sara interpretava a sua atitude como "prova de amor". Aos poucos, foi perdendo as amizades e teve a sua primeira filha, que tinha quatro anos na altura em que a conheci. Quando realizámos a entrevista, já era mãe de novo, de um bebé de seis meses. Contou-me como o pai da sua filha tentou indiretamente provocar um aborto porque não queria que tivesse outro bebé. Ele tinha uma relação com outra mulher, que também tinha engravidado:

"Queria que eu tirasse o bebé. Chateava-me muito, chamava-me nomes. Eu ficava nervosa, a pressão subia. Tudo aquilo para ver se eu abortava porque [com] toda aquela pressão, aquele nervosismo, a pessoa aborta mesmo. Só que eu sou forte, senão perdia o bebé".

Sara usou em casa um tratamento da terra para travar um possível início de aborto espontâneo, não ousando ir sozinha ao hospital e sabendo que Carlos não iria acompanhá-la. Depois de ter nascido a segunda filha, Carlos deixou 
Sara para ficar com a outra mulher. Ficou desempregada, a viver na barraca, num bairro ilegal entre o rio e uma linha férrea, que era preciso atravessar com cuidado, dado que o lugar de travessia era entre dois túneis dos quais poderia surgir a qualquer momento um comboio. A barraca deixava entrar a chuva em certos lugares e a eletricidade era fornecida através de uma ligação clandestina. Os seus pedidos junto da Câmara Municipal para que lhe fosse atribuído um alojamento social foram negados por habitar numa barraca ilegal e por ter um visto temporário. Sara contou como passou uma noite em branco depois de a filha se ter soltado repentinamente da sua mão à beira da linha férrea e ter atravessado no momento em que se aproximava um comboio.

As condições de vida desta mãe cabo-verdiana, partilhadas pelos outros residentes do bairro, constituem um sofrimento social coletivo, definido em função da pobreza material e que deve ser analisado no contexto estrutural da história da emigração de Cabo Verde. De acordo com a teoria de Archer (2000, 2003), os residentes são "agentes" posicionados desfavoravelmente na distribuição escassa dos recursos na sociedade. Porém, sem querer desvalorizar esta dimensão material do sofrimento social, o objetivo desta análise é o de focar o sofrimento social individual, criado através das interações sociais.

A principal razão que Sara apontava para querer sair do bairro não se referia tanto às más condições materiais de vida, como ao seu isolamento social dentro do bairro. Cada vez que saía de casa, os vizinhos insultavam-na. Acordava bem-disposta de manhã, a conviver com as suas filhas, mas, mal punha os pés fora de casa, os vizinhos começavam a chamar-lhe nomes. E, como explicou, não sendo uma mulher para permanecer calada, retribuía, desencadeando uma discussão que lhe tirava toda a boa disposição para o resto do dia. Estava a ser medicada para a depressão e disse-me, várias vezes, que as suas filhas eram a única fonte de alegria na sua vida e que, por elas, tinha de ultrapassar os problemas, pois, se ela se deixasse ir abaixo, se adoecesse, se morresse, quem iria tratar das filhas?

Entendia o seu isolamento social dentro do próprio bairro como fruto de racismo entre os cabo-verdianos. Afirmou que, como eu já vivi em Cabo Verde, não precisava de me explicar a rivalidade que existia entre badius e sampajudus, e acrescentou: "Sampajudu e badiu não dá: é sempre rival". Esta rivalidade corresponde a uma divisão regional dentro do arquipélago que facilmente ganha dimensões raciais, dado que os badius costumam ser mais escuros, se não negros, e os sampajudus mais claros, ou até brancos (Batalha 2004: 74).

Embora Batalha (2004) afirme que, na diáspora, estas rivalidades geralmente desaparecem, tal não aconteceu nas vivências de Sara no microcosmo social da sua vizinhança. Queixava-se de ser mal tratada por todos os vizinhos desde que o pai das suas filhas, que é badiu, se foi embora. As relações entre Sara e os seus vizinhos badius, que tinham sido cordiais antes da saída de 
Carlos, foram piorando, de tal maneira que evitava sair de casa. Sendo ela filha de sampadjudu e de badiu, afirmou que os seus vizinhos tinham inveja "porque o sampadjudu é mais bonito, olho azul, verde, cabelo mais fino. O badiu tem o cabelo mais grosso, sabia?" Como afirma Brubaker, "os que são categorizados são eles próprios categorizadores crónicos” (2004: 68, tradução minha).

Um posicionamento antropológico perante a rivalidade entre badius e sampadjudus obriga-nos a olhar em duas direções ao mesmo tempo. Esta rivalidade, também documentada por outros antropólogos (Meintel 1984), tem de ser analisada como um fenómeno social que é simultaneamente verdadeiro e falso. É verdadeiro como categoria de prática em certos contextos, no sentido em que Brubaker (2004) fala da hiperacessibilidade das categorizações e estereótipos raciais para dar sentido aos acontecimentos. Esta hiperacessibilidade de categorias raciais e étnicas nas representações culturais coletivas faz com que as pessoas interpretem mais rapidamente os eventos em termos étnicos ou raciais do que em outros termos (2004: 79). Porém, esta rivalidade também tem de ser encarada como falsa, no sentido em que é insuficiente como categoria de análise. Em vez de encarar os grupos raciais, étnicos e nacionais como entidades substanciais, eles devem ser vistos como representações coletivas: formas de ver o mundo e de interpretar a experiência social. Cabe ao investigador, não somente analisar como as pessoas são classificadas, mas também como é que palavras, situações, ações e gestos são classificados, interpretados e vivenciados (Brubaker 2004: 77). Este alargamento do horizonte analítico ajuda a ver além das categorizações étnicas.

No caso de Sara, a deterioração das relações sociais com os vizinhos na sequência da saída de Carlos constitui uma situação significativa para o alargamento da análise. Vivendo em proximidade com os seus vizinhos badius, Sara não partilhou com eles a notícia da saída de casa do seu marido, quebrando desta forma as expectativas sociais de reciprocidade que se desenvolvem entre vizinhos que partilham as mesmas condições precárias de vida. Segundo Sara, os seus vizinhos terão interpretado o seu silêncio como sinal de superioridade de sampadjudu. Analisada na perspetiva de Brubaker (2004), podemos afirmar que esta interpretação era a forma mais fácil de dar sentido ao seu comportamento.

Do ponto de vista de Sara, recorrer à rivalidade entre badius e sampadjudus era a forma mais fácil e acessível de dar sentido ao seu sofrimento social, enquadrando-o numa lógica de pertença coletiva. E a sua subjetividade é verdadeira. No entanto, esta rivalidade também tem de ser encarada como falsa, uma vez que é insuficiente como enquadramento da análise do seu sofrimento social. Os dados apontam ainda para a necessidade de se enquadrar o seu testemunho pessoal numa análise, não somente sobre os efeitos materiais da emigração cabo-verdiana de mão de obra pouco qualificada, mas também sobre as relações de género. Várias mães entrevistadas contam como os pais dos seus 
filhos não quiseram assumir a paternidade. ${ }^{4}$ Os meus contactos com mulheres cabo-verdianas também revelaram que Carlos era pai de mais crianças com uma terceira mulher: uma situação que Sara desconhecia.

No seu estudo de relações conjugais na ilha de São Vicente, Åkesson (2004: 102) afirma que o comportamento polígamo é visto como sinal de que se é um "verdadeiro" homem e é consequentemente encarado como algo natural. Todavia, este comportamento não deixa de ser criticado, como demonstra o conteúdo da seguinte conversa entre duas mulheres cabo-verdianas residentes em Portugal, reproduzida a partir das notas de campo:

“- É aquela coisa, às vezes namora com outra. Por isso eu quero um português - comenta uma rapariga ansiosa porque desconfia que está grávida do seu namorado cabo-verdiano em quem pouco confia.

- Será que não são todos iguais? - responde a amiga, que está à espera de um bebé cujo pai também é cabo-verdiano.

- Não, não forçam. Tu dizes 'não quero', e eles aceitam. Cabo-verdiano, não. Dizem que já esperaram muito e querem 'prova de amor'. Se não, vão para outra mulher".

Olhando agora para trás, Sara também lamenta a forma como perdeu as amigas por ter acreditado no discurso de Carlos sobre a sua "prova de amor". Ao refletir sobre o assunto, vemos o árbitro da sua identidade pessoal (Archer 2000) em ação.

"Eu sou uma pessoa... às vezes, dá-me raiva de mim mesmo, eu quando me apaixono por uma pessoa entrego tudo, a cabeça, esqueço tudo à volta... E isto é que faz mal... Elas ficaram todas magoadas. Chegaram a me dizer, disseram: 'Sara, isso não se faz, homem não é certo, mas amigas é sempre certo, porque as amigas, se tu estás em situação grave, elas podem tentar ajudar... e tu nos trocaste todas pelo Carlos'... Agora estou arrependida, também a gente aprende com os erros, agora não faço isso com ninguém".

Estas palavras (gravadas numa entrevista) não podem, no entanto, ser analisadas meramente como uma forma individual de raciocínio, dado que a disposição natural que Sara afirma ter, de ser incapaz de resistir à sedução, corresponde às observações de Åkesson de como as mulheres em São Vicente constroem a "fraqueza" feminina como "algo inerente e inevitável" na sua sexualidade, que "predispõe as mulheres a serem incapazes de resistir

4 Estes dois estudos de caso enquadram-se numa investigação mais alargada sobre jovens mães cabo-verdianas em Portugal. 
a serem conquistadas" (2004: 108, tradução livre). No entanto, se olharmos para as circunstâncias em que Sara foi viver com Carlos, vemos que também se tratava de uma estratégia de sobrevivência. Dado que não se sentia bem no seu trabalho de empregada doméstica interna, numa casa onde achava que estava a ser explorada, juntar-se a Carlos foi uma forma de sair dessa situação. Trocou a sua precária independência económica para desempenhar o papel tradicional cabo-verdiano de "mulher" dependente do "marido" (embora não fossem casados). Sujeitou-se à sua autoridade, perdendo, no processo, as amigas. Seguiu as regras do "contrato", segundo o qual o seu corpo the pertencia, mas era responsabilidade do homem mantê-lo (Massart 2005: 252). Tiveram filhos, o que, segundo Massart, transforma a "namorada" em "mulher" com mais "direitos" para reivindicar a responsabilidade do homem (2005: 252). Terá sido por isto que Carlos não a apoiou durante a segunda gravidez, quando estava em situação de ameaça de aborto espontâneo? Estaria também já sujeito às reivindicações da outra mulher grávida com quem tinha relações? Durante a entrevista, Sara afirmou que os seus vizinhos badius a criticavam por não ter conseguido impedir que o seu marido a deixasse:

"Deitam piada, que eu penso que sou melhor que eles mas que não passo de uma coitada porque, quer dizer, o meu marido fez-me aquilo. Não consegui apresar o meu marido dentro de casa. Porque ninguém não vai apresar ninguém porque ninguém é dono de ninguém. Eles acham que eu não tive pulso, força, para ter o meu marido dentro de casa”.

A falta de "pulso" não correspondia ao novo modelo emergente da feminilidade que, acompanhando as transformações económicas e sociais de Cabo Verde nas últimas décadas, não se submete tão facilmente à dominação masculina, negociando os termos da sua relação (Massart 2005). Vejamos, a título de exemplo deste novo modelo, a afirmação de uma estudante cabo-verdiana que cortou as relações com o pai do seu filho, residente em Cabo Verde, quando ele recusou assinar o termo de responsabilidade para que ela pudesse enviar o filho, nascido em Portugal, para a avó materna em Cabo Verde, de forma a poder continuar com os estudos em Portugal: "Ele não pode mandar em tudo na minha vida. Isso não é vida para mim. Em Cabo Verde, homens mandam nas mulheres, as mulheres não têm voz".

Durante a entrevista que fiz e em todas as ocasiões em que acompanhei Sara nas consultas de pediatria das filhas, o mau relacionamento com os vizinhos parecia constituir a sua maior preocupação. Ciente do desfasamento entre o seu "eu", com o qual se identificava, e um "mim" que lhe era imposto pelos vizinhos - convencida, coitada, sem "pulso" -, a sua identidade pessoal velava pela sua identidade social, pelo seu valor próprio (self-worth) na ordem social. Acreditava que, livrando-se dos vizinhos, iria ultrapassar os 
seus problemas: "Eu tenho certeza que se eu sair de lá vou vencer. Porque eu tenho muita força e as minhas filhas dão-me muita força. Muita! Porque lá é toda uma pressão. Eu saio para a rua e deitam piada porque eu já não falo com ninguém lá..."

Mesmo sem ter acesso aos pontos de vista dos vizinhos badius de Sara e deixando alguma margem de tolerância para as possíveis "distorções" no seu relato, não deixa de ser evidente como as interações sociais dentro do bairro ativaram estereótipos de etnicidade e de género (Brubaker 2004: 76). O papel dos insultos verbais e da má-língua na ativação de categorizações étnicas é salientado por Jenkins:

"Verbal abuse and violence, in particular, are connected with the beating of ethnic boundaries through the enforcement of definitions of what the ethnic 'other' is, or may or must $d o$. Issues of power and control are at the heart of the matter.

Power and control are also central to sexual relationships... Gossip is one of the most effective ways of policing inter-ethnic sex and friendship relationships" (Jenkins 1994: 211-212).

Será que as "piadas" sobre a incapacidade de manter o marido dentro de casa, ao ativar estereótipos de etnicidade, segundo os quais os sampajudus se consideram superiores, serviram para insinuar que Carlos não devia ter relações com uma mulher sampajudu e para afirmar a superioridade e maior poder da mulher badiu?

Do ponto de vista de Sara, estas "piadas"contribuíram para o seu isolamento e sofrimento social. Passava os dias fechada em casa a ver televisão. A vontade e a capacidade de alterar a sua posição involuntária face à distribuição dos escassos recursos da sociedade (Archer 2000), procurando, por exemplo, um novo trabalho, também foram afetadas por estas relações sociais, visto que tinha a "certeza" de "vencer" se saísse do microcosmo do seu bairro. Falava de arranjar uma creche para a bebé e de procurar trabalho, mas o primeiro passo a dar era, sempre, sair do bairro.

O caso analisado em seguida elucida de uma forma patente o argumento de Bourdieu sobre como a experiência do posicionamento na sociedade é afetada pelos efeitos das interações sociais dentro dos microcosmos sociais (1999: 4-5). Neste caso, passamos da vizinhança para o trabalho.

\section{O SOFRIMENTO "POSICIONAL"}

Articular o sofrimento social com questões de identidade foi uma abordagem que surgiu no contexto de uma investigação em curso sobre as vivências de maternidade e de paternidade de imigrantes cabo-verdianos residentes no 
Norte de Portugal. ${ }^{5} \mathrm{O}$ objetivo principal da pesquisa é procurar compreender de que forma estas vivências - transmitidas em narrativas, através de entrevistas e conversas informais, e observadas no dia a dia em consultas médicas - podem contribuir para uma teorização do self.

O trabalho de campo anterior foi orientado por uma perspetiva teórica sobre a hegemonia do poder médico. ${ }^{6}$ Existem muitos estudos sobre como a experiência de gravidez e de parto, em contexto hospitalar, pode alienar a mulher do seu próprio corpo, que é transformado num objeto sobre o qual perde o controlo (Marck 1994; Davis-Floyd e Sargent 1997). Este sentido de alienação, provocado pela hegemonia do conhecimento biomédico, será provavelmente mais forte para a mulher imigrante, dado que as suas vivências culturais não coincidem com a cultura dominante. No seu caso, não somente a experiência de parto, mas também divergências culturais nos cuidados, na forma de tratar o bebé, podem criar sentimentos de alienação que resultam num questionamento do self (Moro, Neuman e Réal 2008). Nesta ótica, os profissionais de saúde podem ser vistos como "instrumentos" de uma ciência biomédica que disciplina os corpos (Foucault 1979) e, nalguns casos, sujeita o "corpo-ser" (Van Wolputte 2004) a uma violência simbólica (Bourdieu 1977).

Porém, a identidade profissional ou ocupacional também constitui uma das mais importantes identidades sociais; além de servir de base para garantir o sustento, também está intimamente ligada ao estatuto social (Jenkins 1994: 205) que é criado através do relacionamento com o "outro":

"[...] a psicodinâmica do trabalho salienta quanto a construção da identidade assenta no campo social, em referência ao necessário olhar do outro: o indivíduo inscreve-se nas relações sociais de trabalho onde são operantes as regras, os códigos próprios e as ideias e o julgamento do outro [...]" (Araújo 2005: 7).

A falta de reconhecimento no trabalho pode ser fonte de sofrimento mental (Araújo 2005) e social. Sara deixou o trabalho, onde sentia que estava a ser explorada, para viver no bairro com Carlos. No estudo de caso que apresento em seguida, vemos como as relações sociais de trabalho podem contribuir para o "sofrimento posicional" (Bourdieu 1999: 4).

5 Contrato de investigação financiado pela Fundação para a Ciência e a Tecnologia, Portugal, ao abrigo do Programa Ciência 2008, e correspondente ao projeto de investigação "Immigrant motherhood at the cross-roads: engaging with self, others and the State".

6 Trabalho de campo desenvolvido no âmbito de uma bolsa de pós-doutoramento da Fundação para a Ciência e a Tecnologia, Portugal (SFRH/BPD/36914/2007), correspondente ao projeto de investigação "Ciência médica, cultura e poder: a produção de saberes 'transfronteiriços' sobre a maternidade". 
Conheci a pediatra Inês quando acompanhei várias mães cabo-verdianas que levavam os seus bebés às consultas no centro de saúde onde ela trabalhava. A pediatra mostrou um interesse ativo pelo meu trabalho e quando conheceu Sara, numa consulta, pediu-lhe autorização para me dar o seu contacto, e foi assim que comecei a acompanhar Sara às suas consultas. Inês também quis ajudar-me a conseguir autorização para desenvolver a pesquisa num hospital e por isso apresentou-me aos seus antigos colegas e, à medida que fomos convivendo e conversando, comecei a ter acesso aos seus pontos de vista.

Habituada a trabalhar no hospital, resolveu mudar de local de trabalho, por razões familiares. A fazer urgências dois fins de semana por mês, e tendo o marido exigências profissionais que também requeriam frequentes ausências de casa, Inês resolveu concorrer a vagas abertas para pediatras nos centros de saúde, de forma a ter mais tempo livre para acompanhar os seus filhos. Quando foi selecionada, pôde escolher entre vários centros de saúde e gostou muito da entrevista que teve com o diretor do centro onde resolveu ficar. No entanto, passado algum tempo, Inês queixava-se agora de que não era bem-vinda. Passava alguns dias inteiros sem ver uma única criança, porque somente um dos médicos de família do centro encaminhava os bebés e as crianças doentes para ela. Explicou-me que a Administração Regional de Saúde colocou pediatras nalguns centros de saúde para descongestionar os hospitais de crianças doentes, mas ela quase nunca via crianças. No início, o diretor do centro tinha sugerido algumas alterações ao seu programa de trabalho, às quais, na altura, não deu importância: dar prioridade aos bebés sem médico de família, ver os bebés dos médicos que estavam de baixa e ver os bebés do diretor, porque, como diretor, não podia ter consultório. Agora, apercebia-se de que a queriam para "tapar buracos", porque não via outros bebés a não ser estes. Inês sentia-se de mãos atadas: "Eles com três meses e eu com cinco anos de especialização! Só faço consultas de rotina! Para quê estar no centro de saúde?"

Contou como o único médico no centro com quem falava um pouco veio pedir-lhe para atualizar o plano alimentar para crianças que estava a ser usado no centro de saúde. Depois de ter feito o plano, o médico, com poder de decisão sobre os programas de atividades a realizar no centro de saúde, recusou aceitar as alterações propostas, alegando que os médicos de família sabiam muito bem o que faziam. Mas, segundo a pediatra, os médicos de família não estavam a par das novas recomendações, porque, por exemplo, não assistiam, como ela, às conferências sobre pediatria.

Tendo notado, durante o meu trabalho de campo, que outros médicos de família, noutros centros de saúde, recomendavam comida sólida aos bebés de quatro meses, perguntei-lhe sobre esta prática e Inês respondeu-me que correspondia às recomendações de há vinte anos e que, agora, se recomendava a amamentação exclusiva até aos seis meses. Esta orientação também está de acordo com as recomendações da Organização Mundial de Saúde, que vi expostas em 
cartazes com fotografias de mães a amamentarem os seus bebés nos serviços de obstetrícia e pediatria dos hospitais.

A pediatra sentia-se isolada. Não convivia com os outros médicos nem com outras pessoas no centro de saúde. Contou-me que, um dia, convidou uma auxiliar de ação médica para tomar café com ela no centro e pagou-lhe o café. Soube depois que a superior hierárquica da auxiliar de ação médica reprovou a auxiliar, dizendo que, nessa instituição, o pessoal de limpeza falava com o pessoal de limpeza, os enfermeiros com os enfermeiros e os médicos com os médicos. Até chegou a ameaçá-la com mudança de local de trabalho. Sem ter acesso aos pontos de vista da superior hierárquica da auxiliar de ação médica, não é possível saber o que ativou esta interdição de sociabilidade, no centro de saúde, entre as categorias profissionais; mas, seja o que for, elucida bem a maneira como uma pessoa pode ser reduzida, num determinado microcosmo social, a uma única pertença. De todas as formas, os efeitos do poder institucional nas relações entre médicos, enfermeiros e auxiliares (Seixas e Pereira 2005; Carapinheiro 1998) oferecem, certamente, um enquadramento contextual significativo para compreender a reação da superior hierárquica.

No seu estudo sobre os serviços hospitalares portugueses, Carapinheiro (1998: 104-105, 79) descreve como a "segregação física" entre médicos, enfermeiros e doentes impõe hierarquias. As regras de circulação no serviço, a definição dos lugares onde cada um deve estar são permanentemente acionadas, servindo como uma forma de controlo social, na qual o saber dos enfermeiros é periférico e o seu poder delimitado pelo poder médico. A afirmação feita pela superior hierárquica da auxiliar de ação médica que tomou café com a Inês, de que o pessoal de limpeza falava com o pessoal de limpeza e os médicos com os médicos, sugere que a mesma cultura de segregação funcionava no centro de saúde. Será que, ao tomar café com a pediatra, a auxiliar de ação médica estava a gozar de um privilégio reservado aos seus superiores? Carapinheiro constatou que só os enfermeiros-chefes entravam, ocasionalmente, na sala dos médicos para resolver certos problemas:

"Ao penetrar neste lugar reforça a sua posição de prestígio hierárquico, fazendo desta possibilidade de convívio direto e informal com os médicos um capital cultural para investir oportunamente noutros domínios da sua ação profissional” (1998: 104).

Mas o poder, como Foucault (1980) salienta, não é depositado nas pessoas. No centro de saúde, onde estava tão isolada, pouco valia à pediatra a sua posição hospitalar de prestígio hierárquico. Se uma criança sujava o chão do seu consultório, ninguém atendia o telefone quando a pediatra ligava a pedir que o fossem limpar. Também veio a descobrir que, no balcão de atendimento do centro, mães e filhos eram mandados embora com o pretexto de que ela estava 
ausente, ou não estava disponível, quando, na realidade, estava sentada no seu consultório sem fazer nada. Começou a aconselhar as mães a irem diretamente ao seu consultório sem passar pela receção.

Também estava a tratar uma depressão que a obrigava a estar de baixa, de vez em quando; no entanto, pedia sempre ao centro de saúde para avisar os seus pacientes, mas veio a descobrir que o pessoal na receção não os avisava e os pacientes chegavam ao centro para ter uma consulta, em vão. Quando voltava para o trabalho, o pessoal administrativo também não avisava as pessoas de que ela já estava de regresso. Às vezes, o pessoal administrativo marcava-lhe as consultas de forma muito inconveniente. Por exemplo, após um período de baixa verificou que o pessoal administrativo tinha marcado um dia inteiro com quinze consultas, seguido de outro dia com uma consulta no início da manhã e outra no fim da tarde, e dias a seguir sem nada. Mesmo sem consultas, era obrigada a ficar o tempo todo no centro de saúde. Inês queixou-se ao colega do centro - o único que lhe encaminhava os bebés - e este respondeu-lhe:

“- Já ouviste falar de um médico queixar-se por falta de trabalho? Escuta, Inês: pagam-te, não pagam?

- Sim, pagam - respondeu a Inês.

- Então estás-te a queixar de quê?"

Esta reação do colega corresponde às atitudes comuns descritas por Bourdieu face ao "sofrimento posicional" dos indivíduos que ocupam uma posição inferior dentro de um universo relativamente privilegiado:

"[...] how painfully the social world may be experienced by people who $[\ldots]$ occupy an inferior, obscure position in a prestigious and privileged universe. The experience is no doubt all the more painful when the universe in which they participate just enough to feel their relatively low standing is higher in social space overall. This positional suffering, experienced from inside the microcosm, will appear, as the saying goes 'entirely relative', meaning completely unreal, if we take the point of view of the macrocosm and compare it to the 'real suffering' of material poverty. This is invariably the point of reference for criticism ('You really don't have anything to complain about'), as for consolation ('You could be worse of, you know')" (Bourdieu 1999: 4).

O argumento do salário não consolava Inês, cuja frustração seria ainda agravada por saber que, se voltasse a trabalhar num hospital, deixaria de ocupar uma posição subalterna.

Tive oportunidade de efetuar alguma triangulação que, ao surgir naturalmente no decorrer do meu trabalho de campo, corroborou as queixas da médica. Enviei uma mensagem de telemóvel à Lisandra - outra mãe que eu 
acompanhava nas consultas pediátricas de Inês - para saber quando era a próxima consulta do seu bebé. Ela respondeu-me que a médica estava doente. Passada meia hora, telefonou-me a dizer que já tinha marcado uma consulta, e que, afinal, a médica já tinha voltado para o trabalho há muito tempo, mas, contrariamente ao prometido, os administrativos não a tinham avisado, nem por carta, nem por telefone. Também conheci uma jovem mãe angolana, à espera de uma consulta de recurso noutro centro de saúde, que, ao conversar com a mãe cabo-verdiana que eu acompanhava, descobriu que ambas conheciam a pediatra Inês e declarou ter desistido das suas consultas. Afirmou que, quando a sua filha tinha à volta de três ou quatro meses, a pediatra adoeceu e o pessoal administrativo do centro ficou de enviar uma carta para casa quando a Dr. ${ }^{a}$ Inês voltasse ao trabalho; no entanto, a carta nunca foi enviada: "Cheguei a ir lá duas vezes com o meu marido mas ela ainda não estava. Depois, não disseram mais nada... Volta e meia tem depressões, esgotamento. Depois resolvi ir ao privado porque não posso estar à espera".

Também observei, no próprio centro de saúde onde a pediatra trabalhava, que havia algum mal-estar nas relações entre Inês e as enfermeiras. Quando acompanhava as mães nas consultas com a pediatra, reparava que, algumas vezes, as enfermeiras pareciam pesar os bebés de má vontade, e ouvi uma vez uma enfermeira comentar à outra: "É a tal situação". Não foi possível conquistar a confiança das enfermeiras para compreender o conteúdo deste comentário, que deixa entender, no entanto, que existia algum descontentamento.

Ao desabafar comigo, Inês afirmou que a cultura do centro de saúde era diferente da cultura dos hospitais e sentia que os médicos de família achavam que o lugar dela era no hospital. Segundo Carapinheiro, a medicina interna - "uma prática de medicina que preserva a perspetiva global e sistémica" (1998: 219) - é desvalorizada nos hospitais face às especializações médicas que ganham mais terreno, prestígio e poder. Colocada num centro de saúde, a Inês estava rodeada de médicos de medicina geral. Poderia a presença de uma pediatra ameaçar a identidade profissional dos médicos de família? Observações de uma consulta de desenvolvimento da criança, noutro centro de saúde, sugerem que poderia ser o caso. Nesta consulta, o pediatra recusou-se a responder às perguntas dos pais porque dizia ser uma questão de ética profissional não interferir com o médico de família.

Se os médicos terão sentido a presença da pediatra como ameaçadora, como compreender a atitude do pessoal administrativo? Conflitos entre o poder médico e o poder administrativo também ocorrem nos hospitais, onde, segundo Carapinheiro, a tentativa de conciliar o exercício da medicina com uma gestão racionalizada dos recursos, de forma a não interferir demasiado com o exercício da profissão médica, é sempre tensa (1998: 134-148). Um caso de exercício de poder administrativo, contado pela Inês, poderá ter contribuído para a desvalorização do papel da pediatra no centro de saúde. 
A pediatra conta que, nos primeiros tempos, recebeu no consultório um pai que ia pedir uma declaração médica sobre a deficiência da filha para poder pedir subsídios à Segurança Social. Como foi sem a criança, a pediatra pediu que marcasse outra consulta e que levasse a criança para ser observada. O pai respondeu: "Para quê? É só uma deficiente, coitada!" Mas marcou a consulta para o dia seguinte. No entanto, não apareceu, e quando, no fim do dia, a pediatra saiu do centro de saúde, viu o pai também a sair, sozinho, de outra consulta médica. Descobriu que o pai tinha conseguido marcar uma consulta com outro médico através da receção e foi queixar-se ao diretor do centro. Achava que o pessoal administrativo e o médico de família tinham respondido aos interesses monetários do pai, em detrimento das necessidades médicas da criança. Já tinha constatado, através do sistema informático, que o pai não levara a criança a nenhuma consulta no hospital. No entanto, o diretor afirmou que não havia problema porque este médico tinha sido nomeado como médico de família do pai, antes da consulta. A funcionária da receção nomeou o médico, sem o consultar, para poder justificar a marcação da consulta sem ter que passar pela pediatra. Inês estava furiosa, por se tratar de um caso grave de interferência no seu trabalho como médica, e por pôr em risco a saúde de uma criança. A partir deste momento, a funcionária na receção deixou de colaborar com ela. De acordo com os relatos da pediatra, este acontecimento específico terá contribuído para o processo do seu isolamento no centro de saúde, reforçando ou ativando rivalidades profissionais, e foi seguido de mais casos de interferência no seu trabalho como médica.

Durante uma consulta na qual participei com a Lisandra e com a sua filha, Inês contou que, quando voltou ao trabalho depois de ter estado doente, várias mães se queixaram de terem sido mandadas embora pelas administrativas sem conseguir ter uma consulta de rotina, porque estas afirmavam que, se o bebé não estava doente, não precisava de consulta. Os bebés ficaram três meses sem serem vistos. Inês afirmou que o desenvolvimento dos bebés jovens precisa sempre de ser monitorizado. Lisandra também se queixou nesta consulta de que, durante a baixa da pediatra, tinha levado a filha ao centro de saúde para que fosse vista por um médico, pois estava com uma tosse muito forte, e que a consulta lhe foi negada por uma enfermeira ao constatar que a criança não tinha febre. Durante a consulta que acompanhei, a pediatra observou a bebé e, embora não tivesse febre, verificou que tinha uma infeção no ouvido. Disse que isto era um bom exemplo de como o pessoal administrativo não devia interferir com o seu trabalho, por não ter conhecimentos adequados.

As interações sociais dentro do microcosmo social do trabalho, onde o pessoal do centro desvalorizava o papel e os conhecimentos da pediatra, contrastam com as interações sociais durante as consultas, entre a médica e os seus 
pacientes, através das quais o "conhecimento autoritativo" (Jordan 1997) foi construído. $^{7}$

\section{CONHECIMENTO, PODER E SOFRIMENTO SOCIAL}

As mães cabo-verdianas levavam os seus filhos às consultas da pediatra Inês porque não tinham médico de família no centro de saúde onde estavam inscritas e existia um acordo, neste sentido, entre os dois centros. Como as consultas da pediatra ficavam mais afastadas do centro da cidade, às vezes, algumas mães optavam pelas consultas de recurso com médicos não especialistas do outro centro de saúde.

Numa das consultas com Lisandra, a pediatra estranhou estar a faltar uma dose na vacina para a bebé, que agora já não poderia ser administrada por ser demasiado tarde, e perguntou quem a tinha receitado. A mãe respondeu que a vacina tinha sido receitada pela médica de recurso: "Mas a médica disse que com um ano é só uma dose". E a pediatra discordou: "Se a médica não explica, a mãe não tem culpa. A mãe não sabe, a enfermeira que lhe dá a injeção também não sabe. A médica tinha que explicar".

Depois da consulta, Lisandra mencionou duas amigas que também só tinham comprado uma dose de vacina para os seus filhos e acrescentou: "Por isso, não gosto de ir àquele centro de saúde. Um médico diz uma coisa, outro médico diz outra coisa. Antes eu ia às consultas dos dois lados, agora só vou aqui. Ela é que é a pediatra".

Jordan (1997: 56) afirma que, em muitas situações, coexistem diferentes sistemas de conhecimento, igualmente legítimos, e as pessoas servem-se de todos, segundo o contexto e as suas necessidades. $\mathrm{O}$ "conhecimento autoritativo" surge quando um tipo de conhecimento ganha mais legitimidade, porque explica melhor o estado do mundo para os objetivos em questão (eficácia) ou porque está associado a uma base de poder mais forte (superioridade estrutural) e, normalmente, por estas duas razões juntas. Uma das consequências disto é que os outros tipos de conhecimento são desvalorizados ou postos de parte.

A forma como os pacientes contribuem para a reprodução do "conhecimento autoritativo", no contexto da consulta, evidencia-se no caso de Sara quando a pediatra, ao constatar que a barriga da sua filha estava dura, recomendou muita água, sopa, legumes e salada e Sara perguntou: "E arroz e carne, não?" A pediatra olhou para ela e, com um ligeiro ar de irritação, respondeu que estava a falar dos intestinos. Pareceu-me, que, ao fazer esta pergunta, Sara estava à procura de uma aprovação da dieta alimentar quotidiana da filha, em

7 O termo “autoritativo" (authoritative) não deve ser confundido com o termo "autoritário", porque o "conhecimento autoritativo" não ganha o seu estatuto através da imposição do poder, dado que a sua legitimidade é construída através do consenso. 
termos gerais. Se nas interações sociais da consulta o conhecimento da pediatra era solicitado, nas suas relações sociais, com os médicos não especialistas, era posto de parte, por exemplo, quando a sua proposta de atualização do plano alimentar para bebés foi rejeitada por um colega.

Será esta desautorização por parte dos colegas que explica o aparente excesso de zelo ou autoridade médica de Inês, em alguns momentos durante as consultas, onde parecia transformar o mais simples saber à volta dos cuidados de bebé num conhecimento exclusivo da profissão médica? Quando Lisandra comentou, por exemplo, que a filha gostava muito de lavar os dentes, a pediatra olhou-a fixamente e perguntou com ar muito sério como é que estava a fazer. A mãe, apanhada de surpresa com a intensidade da pergunta, hesitou, e depois respondeu que estava a usar uma escova de dentes pequena e uma pequena quantidade de pasta de dentes. Inês interrompeu-a, dizendo, num tom intenso e imperativo, que devia pegar na criança, encostá-la com as costas coladas contra ela e a cara virada para frente, que podia usar um banco, porque era pesada, mas para ter cuidado para que não caísse, e depois escovar para cima e para baixo com uma escova pequena e qualquer pasta de dentes. A expressão na cara de Lisandra parecia revelar um sentimento de surpresa misturado com um ligeiro divertimento.

A forma como o conhecimento da pediatra era valorizado nas consultas e posto de parte pelo pessoal do centro corrobora o argumento de Jordan (1997: 59) de que são as interações sociais que determinam, em cada contexto, que tipo de conhecimento pode ser produzido e manifestado e que outro não é permitido.

Os conflitos com o pessoal administrativo e médico no centro de saúde começaram a afetar a vida pessoal da pediatra. Ela manifestou o desejo de proteger a sua família, ao afirmar que não podia deixar a sua situação profissional afetá-la demasiado, porque esta tinha contribuído para a sua depressão e quem sofria as consequências eram os seus filhos e marido. Sara tinha feito uma afirmação parecida quando disse que tinha de tentar ignorar os vizinhos badius porque, se ela adoecesse ou morresse, não sabia quem tomaria conta das suas filhas.

Os casos de sofrimento social analisados aqui não são mediáticos; não se trata de situações extremas de violência ou brutalidade. Trata-se do "sofrimento vulgar" (Bourdieu 1999) que ocorre no quotidiano, trata-se da "faca mole" - soft knife - (Kleinman, Das e Lock 1996) de processos rotineiros de opressão, onde as "palavras não são inocentes" (Maalouf 2003: 22) e ferem subjetividades. O enfoque do argumento de Brubaker (2004: 77-78), sobre como a etnicidade é ativada quase automaticamente, de forma não consciente ou deliberada, chama a nossa atenção sobre como os atores veem e interpretam o mundo social. A afirmação da superior hierárquica da auxiliar de ação médica de que os auxiliares só falam com os auxiliares e os médicos só falam com os 
médicos equipara-se à afirmação de Sara de que "Sampajudu e badiu, não dá: é sempre rival". Neste caso, pouco interessa ao investigador tentar classificar os atores sociais. Vimos como, em ambos os casos, foi a partir de circunstâncias particulares que as categorizações sociais foram ativadas, criando crispações nas relações sociais.

Ambos os casos discutidos aqui abrem fissuras nas categorias que habitualmente condicionam o nosso olhar sobre os processos de sofrimento social (Kleinman, Das e Lock 1996). Não se trata da opressão do imigrante africano pelo nativo europeu e também não se trata unicamente da hegemonia do poder médico face ao paciente. É a partir destas fissuras que vemos como o poder é implicado na construção social de identidades (Jenkins 1994: 219) e reconhecemos a necessidade de olharmos simultaneamente em duas direções opostas, atentos à diferença entre uma categoria de prática e uma categoria de análise (Bourdieu 1977; Brubaker 2004). E é também a partir destas fissuras que reconhecemos a utilidade de se fazer análise comparativa. O sofrimento social de duas mulheres com estatutos sociais diferentes e com posicionamentos desiguais face à distribuição dos recursos da sociedade foi, contudo, vivenciado e expresso, em cada caso, através das pertenças, revelando processos sociais e vivências semelhantes que apontam para a nossa humanidade comum (Archer 2000). Se a noção de uma humanidade comum não for posta em causa pelo investigador, o seu reconhecimento nem sempre está presente nas categorias da prática dos atores sociais que criam barreiras insuperáveis entre o "eu" e o "outro" que acabam, em alguns casos, por gerar situações extremas de violência. Explorar como o sofrimento social pode ser vivenciado através das identificações e das pertenças constitui um excelente ponto de partida para responder ao desafio de Bourdieu (1999) de alargar os nossos horizontes de forma a que a pobreza material não seja o único critério utilizado para reconhecer e compreender a natureza do sofrimento social nas sociedades contemporâneas. 


\section{BIBLIOGRAFIA}

ÅKESSON, Lisa, 2004, Making a Life: Meanings of Migration in Cape Verde. Gotemburgo, Departamento de Antropologia Social, Universidade de Gotemburgo, dissertação de doutoramento.

ARAÚJO, Clara, 2005, "Sofrimento e prazer no trabalho", Revista do Instituto Politécnico de Viana do Castelo, 2: 5-8.

ARCHER, Margaret, 2000, Being Human: The Problem of Agency. Cambridge, Cambridge University Press.

— 2003, Structure, Agency and the Internal Conversation. Cambridge, Cambridge University Press.

BATAlHA, Luís, 2004, The Cape Verdean Diaspora in Portugal: Colonial Subjects in a Postcolonial World. Oxford, Boulder e Nova Iorque, Lexington Books.

BOURDIEU, Pierre, 1977, Outline of a Theory of Practice. Cambridge, Cambridge University Press.

—, 1999, “The space of points of view”, em Pierre Bourdieu et al. (orgs.), The Weight of the World: Social Suffering in Contemporary Society. Cambridge, Polity Press, 3-5.

BRUBAKER, Rogers, 2004, Ethnicity without Groups. Cambridge, Harvard University Press.

CARAPInHeIro, Graça, 1998, Saberes e Poderes no Hospital: Uma Sociologia dos Serviços Hospitalares. Porto, Afrontamento.

CARLING, Jorgen, e Lisa ÅKESSON, 2009, "Mobility at the heart of a nation: patterns and meanings of Cape Verdean migration”, International Migration, 47 (3): 123-155.

DAMÁSIO, António, 2000, The Feeling of What Happens: Body, Emotion and the Making of Consciousness. Londres, Vintage Books.

DAVIS-FLOYD, Robbie E., e Carolyn F. SARGENT (orgs.), 1997, Childbirth and Authoritative Knowledge: Cross-Cultural Perspectives. Berkeley, University of California Press.

FOUCAUlt, Michel, 1979, Discipline and Punish: The Birth of the Prison. Harmondsworth, Peregrine Books.

_-1980, Power/Knowledge: Selected Interviews and Other Writings, 1972-7. Nova Iorque, Pantheon Books.

JENKINS, Richard, 1994, "Rethinking ethnicity: identity, categorization and power", Ethnic and Racial Studies, 17 (2): 197-223.

JORDAN, Brigitte, 1997, "Authoritative knowledge and its construction", em Robbie E. Davis-Floyd e Carolyn F. Sargent (orgs.), Childbirth and Authoritative Knowledge: CrossCultural Perspectives. Berkeley, University of California Press, 55-79.

KLEINMAN, Arthur, Veena DAS, e Margaret LOCK (orgs.), 1996, "Introduction", Daedalus, 125 (1): 25-45.

MAALOUF, Amin, 2003, In the Name of Identity. Londres, Penguin Books.

MARCK, Patricia Beryl, 1994, "Unexpected pregnancy: the uncharted land of women's experience”, em Peggy Anne Field e Patricia Beryl Marck (orgs.), Uncertain Motherhood: Negotiating the Risks of the Childbearing Years. Londres, Sage Publications, 82-138.

MASSART, Guy, 2005, "Masculinités pour tous? Genre, pouvoir et gouvernementalité au Capt-Vert”, Revue Lusotopie, XII (1-2): 245-262.

MEINTEL, Deidre, 1984, Race, Culture and Portuguese Colonialism in Cabo Verde. Syracuse, Nova Iorque, Maxwell School of Citizenship and Public Affairs, Syracuse University. 
MORO, Marie Rose, Dominique NEUMAN, e Isabelle RÉAL, 2008, Maternité en exil: Mettre des bebés au monde et les faire grandir en situation transculturelle. Paris, Éditions La Pensée Sauvage.

SEIXAS, Paulo, e Pedro PEREIRA, 2005, Relações e Situações Críticas na Enfermagem. Porto, Universidade Fernando Pessoa.

VAN WOLPUTTE, Steven, 2004, "Hang on to your self: of bodies, embodiment, and selves", Annual Review of Anthropology, 33: 251-269.

Identity and belonging: beyond the material dimensions of social suffering - Elizabeth Pilar Challinor - Centro em Rede de Investigação em Antropologia (CRIA-UM), Universidade do Minho, Portugal • e.p.challinor@gmail.com

An anthropological view of social relations in the microcosms of a neighbourhood and a health centre reveals the limitations of using material poverty as the sole criterion for understanding processes of social suffering. In order to explore the ways in which social suffering may be experienced through identifications and belonging, ethnic and professional identity are both examined as examples of social identity. The dialectic relationship between social and personal identity shows how power is not deposited in people, but rather depends upon their social relations. Since the exercise of power is not guaranteed by the mere status of a given social category, we need to focus on the experiences and subjectivities to be found in the cracks between categories, always on guard to distinguish between categories of practice and categories of analysis, in order to widen our horizons regarding the nature of processes of social suffering.

KEYWORDS: Cape Verde, identity, biomedicine. 